\title{
Additional records of the Long-eared Hedgehog, Hemiechinus auritus (Gmelin, 1770) (Erinaceomorpha: Erinaceidae) from Fars Province, southern Iran
}

\author{
Ali Gholamifard ${ }^{1 *}$ and Bruce D. Patterson ${ }^{2}$ \\ ${ }^{1}$ Department of Biology, Faculty of Sciences, Lorestan University, 6815144316 Khorramabad, Iran \\ ${ }^{2}$ Negaunee Integrative Research Center, Field Museum of Natural History, Chicago IL 60605-2827, USA \\ Corresponding author ${ }^{\boxplus}$ : gholamifard.a@lu.ac.ir
}

\begin{abstract}
Iran is home to three genera and four species of hedgehogs in the family

Received: 28 November 2019

Accepted: 20 December 2019

Published online: 31 December 2019 Fars Province. In the present study, we report two new distribution records of the Long-eared Hedgehog, Hemiechinus auritus from the southwestern region of Fars Province (Varavi Mountain in Mohr and Lamerd Townships in the southern Zagros Mountains), marking a range extension for this species in southern Iran.
\end{abstract}

Key words: Hedgehogs, Hemiechinus auritus, Zagros Mountains, Fars Province, Iran

\section{Introduction}

Knowledge concerning the mammal fauna of Iran continues to grow. It was thought to include 191 species belonging to 93 genera and 10 orders (Karami et al., 2008), but has subsequently grown to 194 species (Ziaie, 2008), and 199 species (Karami et al., 2016), respectively. The small order of Erinaceomorpha Gregory has 10 genera and 26 species distributed in Africa, Asia and Europe (Karami et al., 2016; Best, 2019).

In Iran, the order Erinaceomorpha is represented by four species belonging to three genera in one family (Erinaceidae). These include the Eastern European Hedgehog, Erinaceus concolor Martin from Golestan, Mazandaran, Guilan, West Azarbaijan, Kordestan and highlands of Tehran and Qazvin Provinces (Fig. 1A, B); Long-eared Hedgehog, Hemiechinus auritus (Gmelin) from Khorasan Razavi, Golestan, Semnan, Tehran, Qazvin, Esfahan, Markazi, Kordestan, Lorestan, Khuzestan, Kerman, and Sistan and Baluchestan Provinces; Desert Hedgehog, Paraechinus aethiopicus (Ehrenberg), only recorded from the Tonb-e Bozorg (Greater Tonb) Island in the Persian Gulf, Hormozgan Province; and Brandt's Hedgehog, Paraechinus hypomelas (Brandt) from throughout Iran, with the exception of northern forested areas and northwestern parts of the country, as well as the Iranian islands of the Persian Gulf such as Qeshm, Hengam, Hormoz, Larak, Khark, and Greater Tonb (Hormozgan and Bushehr Provinces) (Karami et al., 2008; 2016).

In this study, we record the first occurrence of $H$. auritus in Fars Province, in southern Iran, and thus add another species of mammals to the fauna of Fars Province. 

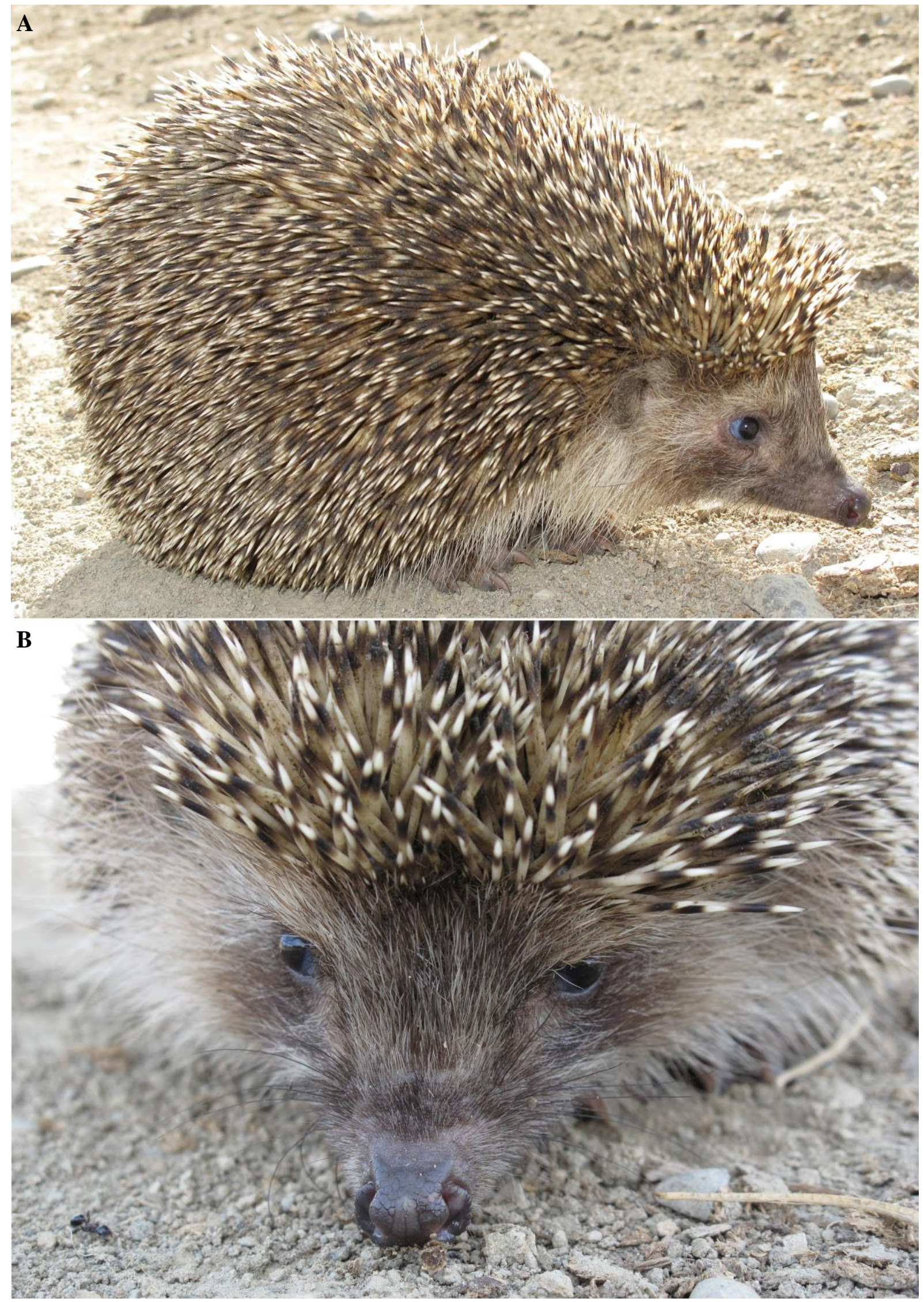

Figure 1: Erinaceus concolor (A), and its anterior region (B) from Koredestan Province. Photos by Ali Gholamifard. 


\section{Material and Methods}

The results of this study are based on several scaterred field observations in southern and western Iran. Figure 2 shows the localities of new records in Mohr and Lamerd Counties in the southwest of Fars Province, southern Iran.

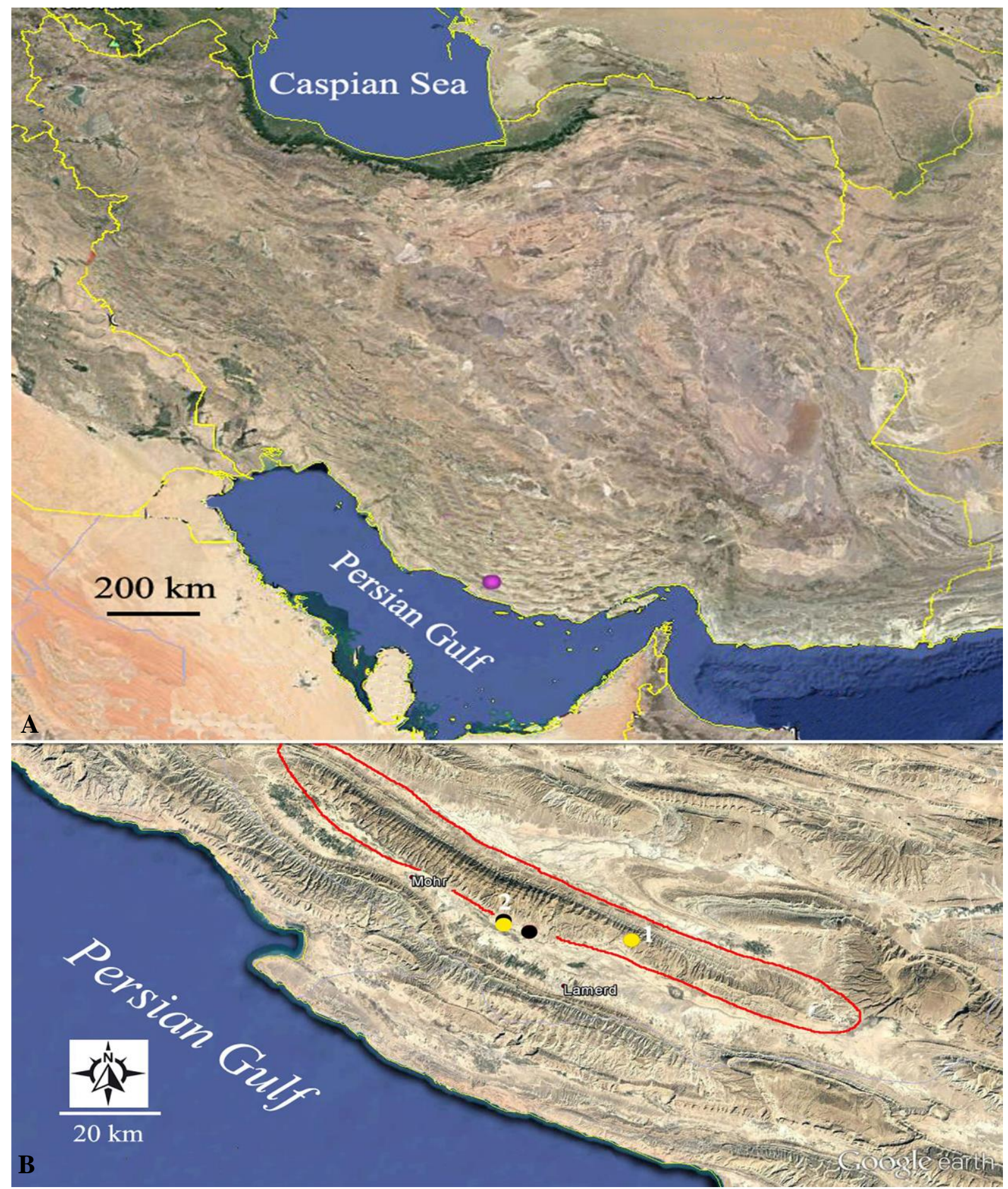

Figure 2: Map of Iran (A) showing the location of Hemiechinus auritus (pink circle) at Varavi District in Fars Province; selected section of Iran map along the Persian Gulf (B) showing Varavi Mountain with red line, and new localities of $H$. auritus (yellow circles 1 and 2) and Paraechinus hypomelas (black circles), respectively. Map from Google Earth (www.earth.google.com). 


\section{Results}

The earliest memory of the first author concerning hedgehogs harkens back to childhood, about 32 years ago, when his grandfather kept two hedgehogs in his wheat mill in southwestern Fars Province for controlling pests and snakes. One of the specimens was black and the other was wheat colored.

The local name of hedgehog in the south of Fars Province is "ZooZoo", while in Lorestan Province in western Iran it is "ZhooZhoo." In the Lorish dialect in the west and south of Iran, the name refers to having an unkempt or disheveled appearance.

Subsequently, the first author as a zoologist has had a more scientific focus on the mammals of Fars Province, noting where hedgehog specimens were found at the night in desert areas or were killed on the roads by motor vehicles (Fig. 3). Most of the observed specimens were blackish (Fig. 4) but in rare cases they were yellowish. One H. auritus individual (Fig. 3) was found dead on 25 March 2008 in the "Chah Shour Pass" $\left(27^{\circ} 25^{\prime} 56.38^{\prime \prime N}\right.$; 53 $\left.3^{\circ} 18^{\prime} 30.41^{\prime E}\right)$, a mountain pass in the southern Zagros Mountains, about $15 \mathrm{~km}$ from the city Lamerd, capital of Lamerd County in southwest of Fars Province (Fig. 2). Its habitat, part of Varavi Mountain, grows on calcareous soils with scattered bushes and trees. The second $H$. auritus (Fig. 5) was found during the night on 22 July 2018 in Varavi City (27²7'51"N; 533'44"E), Mohr County in southwest of Fars Province. The northeast end of the city is near the foothills of Varavi Mountain and close to palm gardens (Fig. 6).

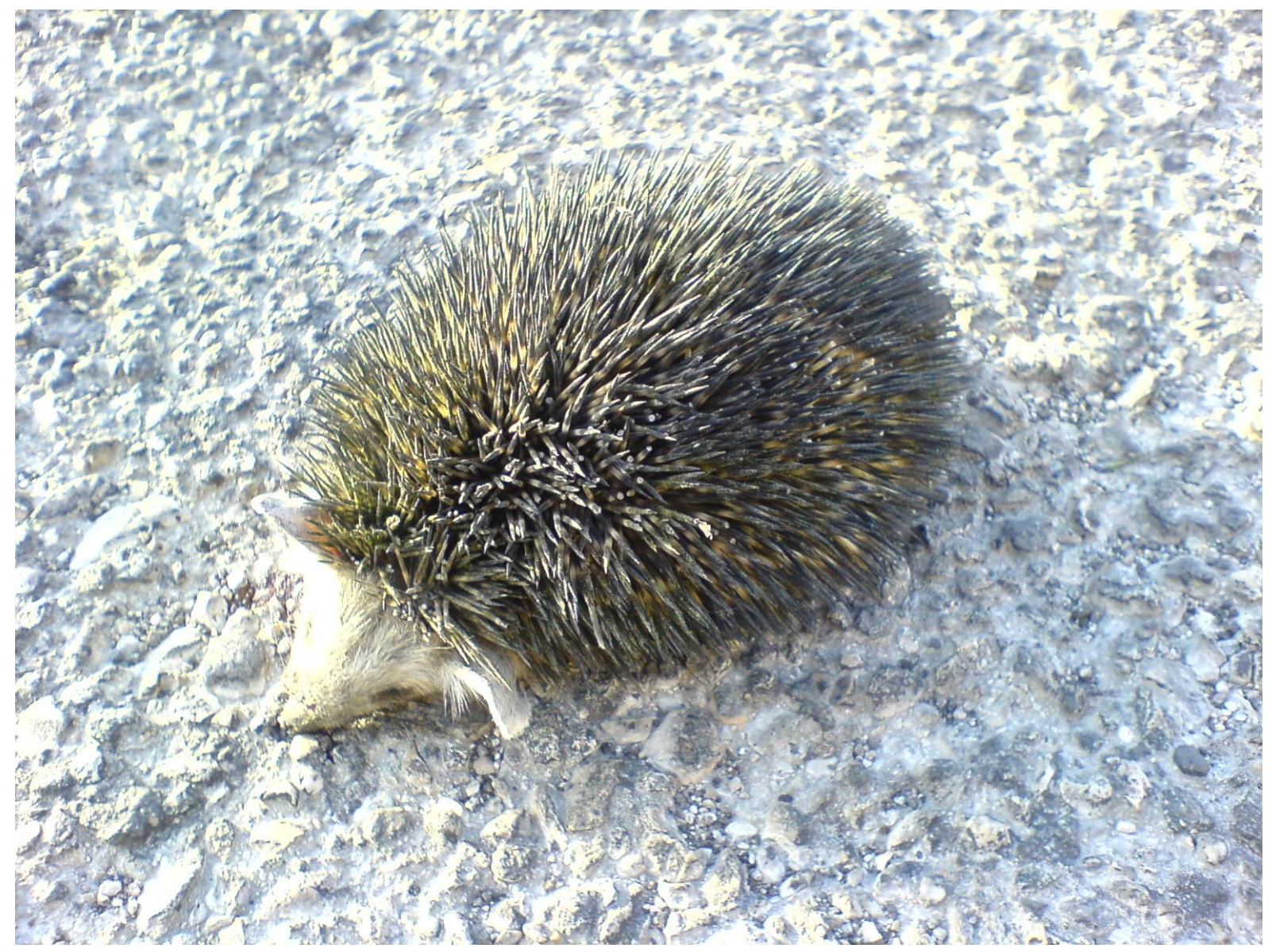

Figure 3: A Hemiechinus auritus on the road surface killed by motor vehicle, in Lamerd region, southwestern Fars Province. Photo by Ali Gholamifard. 


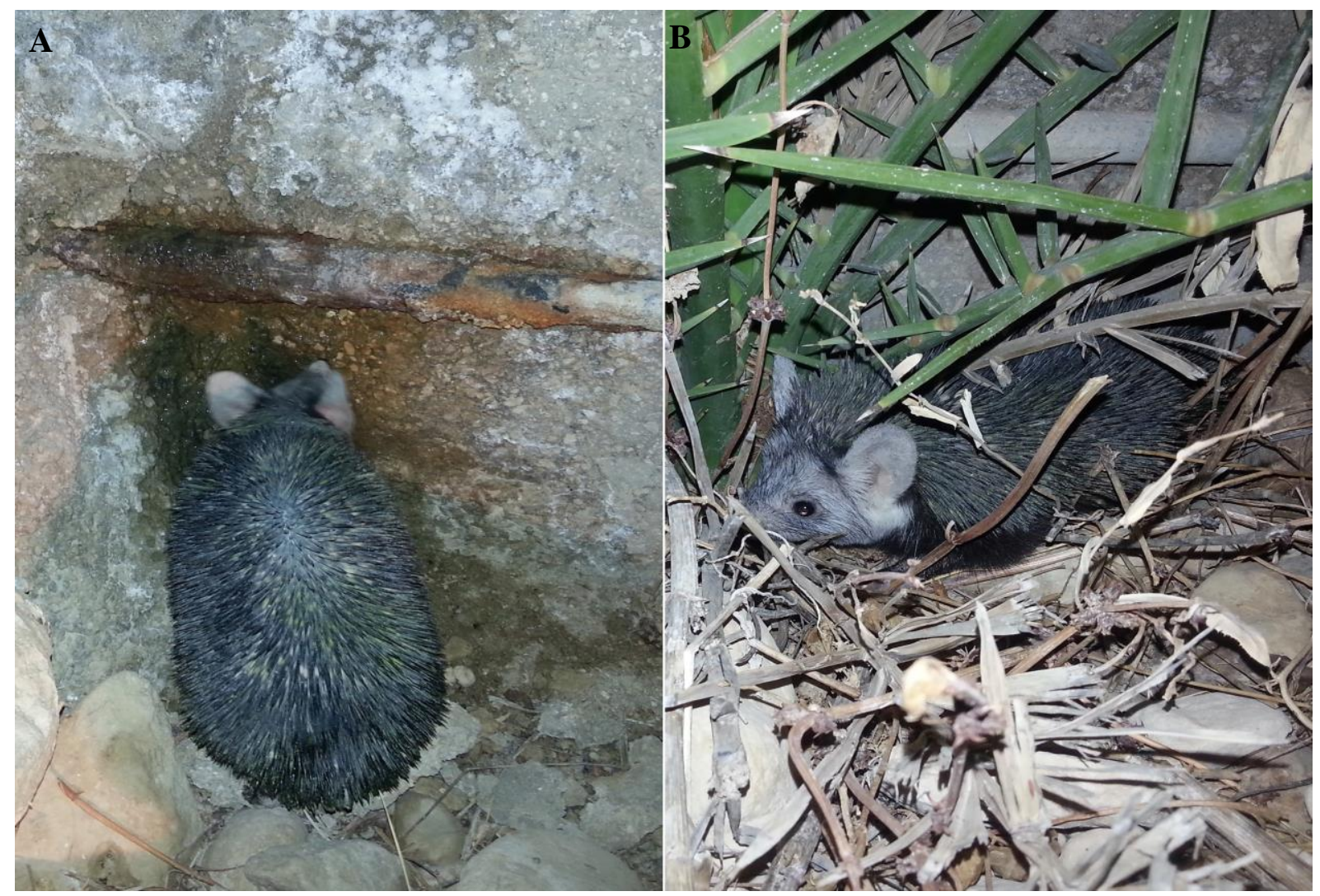

Figure 4: Paraechinus hypomelas from Varavi District, southwest of Fars Province. Entering residential areas for drinking water during summer (A), hiding behavior in the bush (B). Photos by Ali Gholamifard, 13 August 2015.

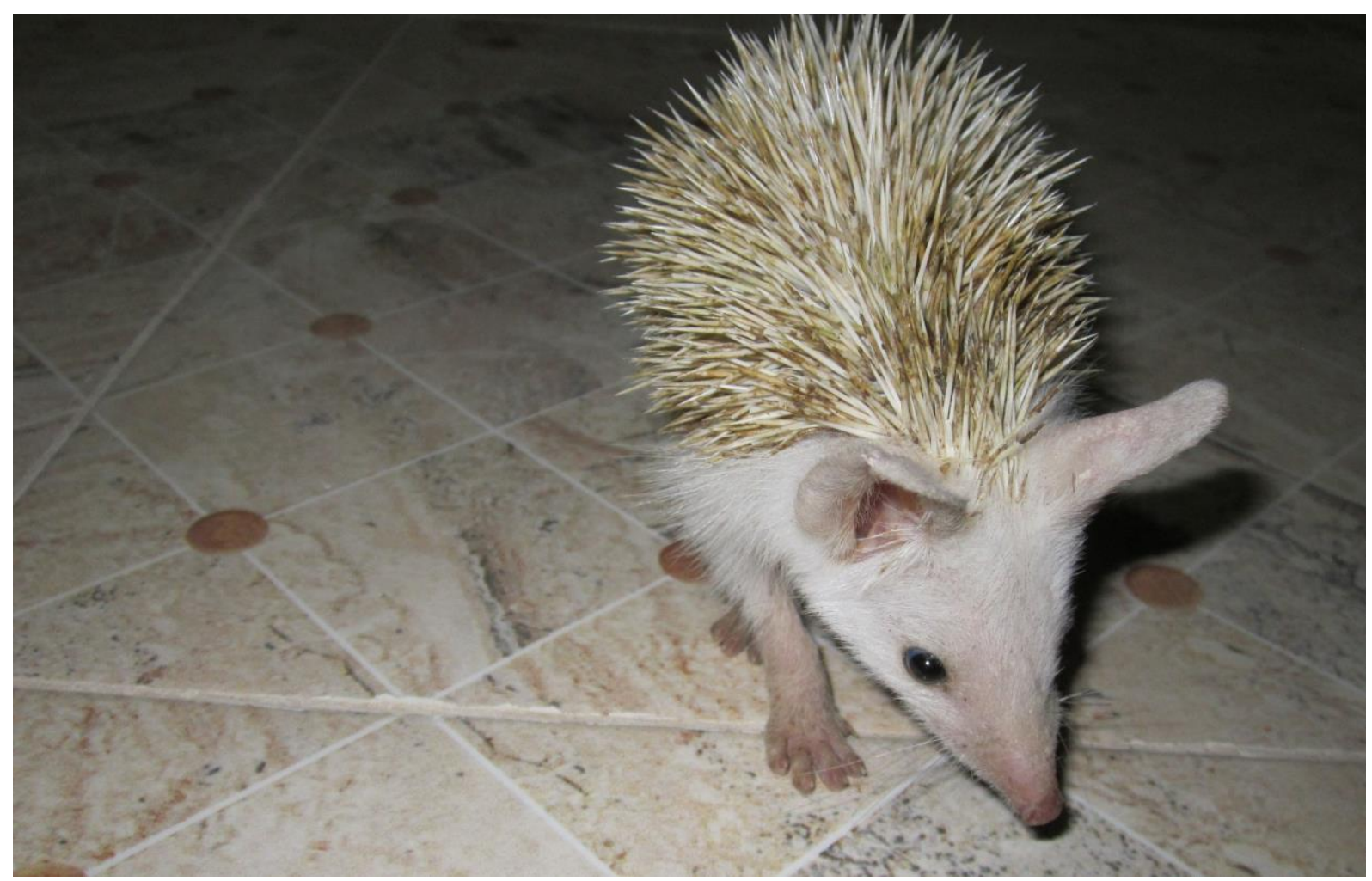

Figure 5: Hemiechinus auritus, in very brief captivity, from Varavi District, southwest of Fars Province. Photo by Ali Gholamifard. 

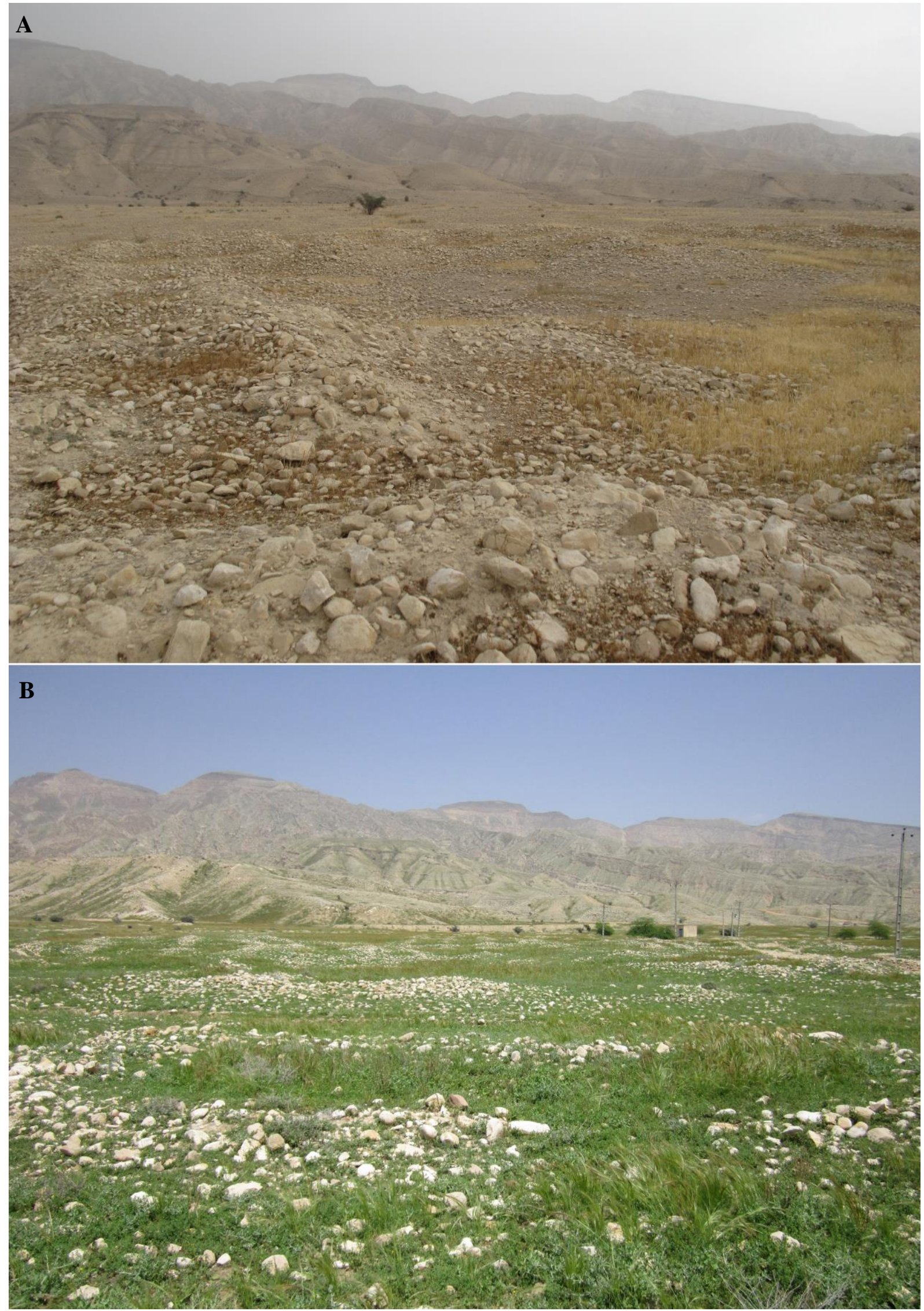

Figure 6: New locality record of Hemiechinus auritus, in hillside of the Varavi Mountain, northeast of Varavi city, southwest of Fars Province in March 2016 (A) and the same habitat in April 2019 (B), respectively. Photos by Ali Gholamifard. 
The specimen of Long-eared Hedgehog was released in the same habitat after being photographed. In these habitats of Fars Province, Hemiechinus auritus is sympatric with Paraechinus hypomelas (Fig. 2B).

Varavi Mountain in the southern part of the Zagros Mountains is a massif $124 \mathrm{~km}$ long and 4$8 \mathrm{~km}$ wide about $45 \mathrm{~km}$ from the Persian Gulf (Fig. 2). It extends from the western border of the Mohr Township to the eastern border of Lamerd Township, both in the southwest of Fars Province. The vegetation of Varavi Mountain consists of different species of thorny bushes (Astragalus), seasonal herbaceous cover, scattered wild Ziziphus trees, and sparse wild pistachio Pistacia atlantica Desfontaines (common name in Persian is Baneh), wild almond trees Amygdalus scoparia Spach, and wild fig Ficus sp. (Gholamifard et al., 2019).

\section{Discussion}

The type locality of H. auritus is the "Astrakan Oblast; Astrakhan" in Russia (Lay, 1967), and the species is distributed in Palaearctic Asia and northern Africa (Ziaie, 2008; Best, 2019). Two species of long-eared hedgehogs from Iran were distinguished by Lay (1967): H. auritus from Khorasan, Golestan, and Qazvin Provinces (in northern Iran), and Kordestan and Khuzestan Provinces (in western Iran), and H. megalotis (Blyth) from Kerman, Sistan, and Baluchestan Provinces in southeastern Iran. The type locality of H. megalotis is "Candahar" (= Kandahar or Qandahar) in Afghanistan (Lay, 1967), while H. a. megalotis has been recorded from Zabol, Sistan and Baluchestan Province, in southeastern Iran (Morshed and Patton, 2002).

Based on the small genetic distance of the mitochondrial cytochrome $b$ gene $(0.3 \%$ Kimura 2parameter distance) between populations of $H$. auritus and $H$. megalotis from Kerman and Sistan and Baluchestan Provinces, respectively, H. a. megalotis is now considered as a subspecies of $H$. auritus (Morshed and Patton, 2002).

According to Lay (1967), Hemiechinus auritus is not an abundant species in Iran, as the specimens collected by Morshed and Patton (2002) were few (two specimens). In their checklist of mammals of Fars Province, Zarei et al. (2019) only recorded Brandt's Hedgehog, Paraechinus hypomelas, without giving details of its distribution in the province. In the southwest of Fars Province, H. auritus is sympatric with P. hypomelas and the latter species is more common.

Finally, molecular studies are needed to clarify the taxonomy and phylogeny of these lovely creatures in Iran, especially in the Zagros Mountains.

\section{References}

Best, T. L. (2019). Family Erinaceidae (Hedgehogs, Moonrats and Gymnures), In: Wilson, D. E. and Mittermeier, R. A. (Eds.), Handbook of the Mammals of the World, Volume 8: Insectivores, Sloths and Colugos. Lynx Ediciones, Barcelona, Spain. pp. 288-331.

Gholamifard, A., Rastegar-Pouyani, N. and Rastegar-Pouyani, E. (2019). A new species of the genus Microgecko Nikolsky, 1907 (Sauria: Gekkonidae) from the southern Zagros Mountains, Iran. Zootaxa, 4648 (3): 435-454. https://doi.org/10.11646/zootaxa.4648.3.2

Karami, M., Ghadirian, T. and Faizolahi, K. (2016). The Atlas of Mammals of Iran. Jahad Daneshgahi, Kharazmi Branch, Karaj, Iran. 292 pp. [in Persian and English]

Karami, M., Hutterer, R., Benda, P., Siahsarvie, R. and Kryštufek, B. (2008). Annotated check-list of the mammals of Iran. Lynx (Praha), 39 (1): 63-102. 
Lay, D. M. (1967). A study of the mammals of Iran resulting from the Street Expedition of 1962-63. Fieldiana: Zoology, 54: 1-281. https://biodiversitylibrary.org/page/2768294

Morshed, S. and Patton, J. L. (2002). New records of mammals from Iran with systematic comments on hedgehogs (Erinaceidae) and mouse-like hamsters (Calomyscus, Muridae). Zoology in the Middle East, 26 (1): 49-58. https:// doi.org/10.1080/09397140.2002.10637921

Zarei, F., Kafaei, S. and Esmaeili, H. R. (2019). Annotated checklist and conservation status of mammals of Fars Province, southern Iran. Journal of Threatened Taxa, 11 (1), 1308713113. https://doi.org/10.11609/jott.4231.11.1.13087-13113

Ziaie, H. (2008). A Field Guide to the Mammals of Iran. First Edition. Iran Wildlife Center, Tehran. 426 pp. [in Persian] 